\title{
VIRTUALIZATION AND CLOUD COMPUTING - CONCEPTS
}

\author{
Miguel Cássio Ferreira Lavrador and António Jorge Gonçalves de Gouveia \\ Universidade de Trás-os-Montes e Alto Douro, Quinta de Prados, 5000-801 Vila Real, Portugal
}

\begin{abstract}
Nowadays, the relationship between competitiveness and technology is spread around the business sector. This technological reality transforms the business scenario and gives a new look over subjects that were thought of as optimized and completely stable. Still, this can threaten the survival of some companies, as well as allow the creation of others, promote new markets and make it easier to globalize. Virtualization and cloud computing present themselves as technologies capable of that transformation as a business scenario, even more effective if used together.
\end{abstract}

\section{KEYWORDS}

Virtualization, Cloud Computing, Outsourcing Services

\section{INTRODUCTION}

Following the rapid development of data / information processing and storage technologies and the success of the internet, computing resources have become cheaper and more powerful than ever. Virtualization and cloud computing are presented as technologies that can make this transformation of the business scenario more effective if used together.

The virtualization consists, fundamentally, in the conception and emulation of isolate environments capable of using multiple operating systems - that are called environments or virtual machines (VM) - inside the same physical machine. On the other hand, cloud computing is a group of services with different typologies and models of implementation, that allows its users, not only multiple network and storage services, but also applications and platforms though the cloud which have a great number of advantages.

Both of these concepts, have the objective of augmenting the efficiency of a physical machine, using, for this the total capacity of hardware and usage of resources.

\section{VIRTUALIZATION - DEFINITION}

Virtualization is the emulation of isolated environments capable of using different operating systems (OSs) within the same machine providing a layer of abstraction of the true resources of a machine (Coelho, Calzavara, \& di Lucia, 2008), enabling virtual hardware to each system.

There are several forms of virtualization, including:

- Server Virtualization: This technique has the purpose of splitting the resources of a physical server, allowing the user to use different isolated OSs simultaneously and on the same hardware, maintaining isolation and security. (Dunamys, 2017) (Souza, Borge, Borges, \& Assis, 2016);

- Application Virtualization: Allows application architecture to be centralized on a single device, making it available to any terminal whenever needed. (Dunamys, 2017) (Souza et al., 2016);

- Desktop Virtualization: This type of virtualization consists of running multiple virtual desktops (OSs, applications, processes...) on a physical server. (Dunamys, 2017) (Guerreiro, 2017);

- Network Virtualization: Provides the creation of logical networks over a single shared physical network infrastructure. Each network has the ability to provide you with full network services, identical 
to those used by a traditional non-virtualized network, with dedicated resources and independent security policies. (Guerreiro, 2017);

- Presentation Virtualization: This type of virtualization is intended for the simultaneous use of an application (installed on a server) by multiple independent users, each with their own individual session. (Shields, 2011) (Obasuyi \& Sari, 2015).

- Data Virtualization: Aims to centralize data storage across one or more hardware components, enabling multiple heterogeneous storage units to be viewed as a robust, centralized homogeneous feature set, ensuring greater security and access performance to the data (Guerreiro, 2017).

\subsection{How it Works}

In a virtualization solution there are two fundamental elements: the host (host system) and the guest (virtualized system to be run by the host). How these two elements interact with each other varies depending on the technique and virtualization tools used. As for existing virtualization techniques, there are full virtualization, paravirtualization and dynamic recompilation.

In full virtualization, the guest executes the instructions as if it worked directly on the OS for which it was designed (Carissimi, 2008). This type of virtualization is the most flexible on the guest operating system, however, causes some loss in processing performance. (Saleem, 2017).

Paravirtualization is an alternative approach to full virtualization. In this virtualization technique, the host system is modified to interact with the VM monitor by selecting instructions to be interpreted on it or directly on the host hardware. (Carissimi, 2008). Its main advantage is that applications can achieve values closer to maximum capacity. Additionally, the complexity of the VMs to be created decreases. (Saleem, 2017).

Finally, in dynamic recompilation, program instructions are translated during program execution through bit strings that are later grouped into high-level codes. This results in better tuning of the generated code to the virtualization environment, but more storage will be required.

\subsection{Advantages and Disadvantages}

Using virtualization results in many benefits, such as:

- Cost-savings: By making better use of existing resources, the need for new equipment decreases, as well as the consequent expenses with installation, physical space, maintenance, cooling and energy consumption (Mattos, 2008). According to VMware, this cost reduction ranges from 29\% to $64 \%$ (Menascé, 2005);

- Efficiency: Running multiple services on the same server makes better use of hardware reducing machine idleness;

- Centralized management: It depends on the virtualization solution used, it is simpler to control the running services, since they are managed centrally;

- Security: When using VMs you can define the best environment to run each service. In addition, the vulnerability of a service will never harm others (Mattos, 2008);

- Platform diversity and testing environment: A wide range of platforms can be deployed, so you can perform performance tests on a particular application or evaluate or upgrade a new system before you actually deploy it;

- Faster deployments: Software installations are faster and simpler since the infrastructure is already installed and there is full application compatibility;

- Legacy application support: Virtualization is extremely useful for applications that run on legacy systems that is old but essential to the business (Souza et al., 2016) (Mattos, 2008).

This type of solution also has some disadvantages, including:

- Security: Because they are located over a software layer and as such it may be subject to vulnerabilities. If the host OS has any vulnerability all VMs hosted there are vulnerable (Carissimi, 2008);

- Management: Virtual environments need to be instantiated, monitored, configured, maintained and stored, which becomes a very arduous task (Carissimi, 2008); 
- Performance: The numbers point to the existence of an extra cost introduced by virtualization but, since it is not very significant, the conclusion is that its use does not have an important impact on the realization of a service (Carissimi, 2008).

\section{CLOUD COMPUTING - CONCEPT}

O cloud computing is a set of principles and approaches that enables users to make network resources, storage, platforms and applications available through the cloud (Saleem, 2017)..

Using this technology allows remote access to software, file storage and data processing over the internet.

Cloud computing uses the connectivity and large scale of internet dispersion around the world to host the most diverse resources, allowing the user to access through a simple device with a browser and a good internet connection (Giraldo, 2018).

\subsection{Typology}

Nowadays, cloud computing offers a wide range of services, tools and features to provide the customer/business with the service that best suits their specific needs. Among others, three models stand out:

- SaaS - Software as a Service: Business applications are contracted on the service model rather than the purchase of software licenses and are managed i.e. updated and corrected by the service provider (Sareen, 2013). SaaS represents the highest level service available in a cloud (Ruschel, Zanotto, \& da Mota, 2010).

- PaaS - Platform as a Service: In this model, a development environment is rented that provides the consumer with the ability to develop their infrastructure or applications in the cloud using vendor-supported programming and tools (Ruschel et al., 2010).

- IaaS - Infrastructure as a Service: Infrastructure resources such as servers and other computing resources are leased. In this model, the consumer does not manage or control the underlying cloud infrastructure, but has control over the deployed OS, storage, and applications (Ruschel et al., 2010).

\subsection{Advantages and Disadvantages}

Adopting a cloud computing service has several benefits, such as:

- Cost-saving: There is a reasonable reduction in infrastructure costs due to the elimination of investments in hardware purchases, software licenses and equipment maintenance (Giraldo, 2018);

- Convenience and centralization of information: It makes the task of accessing data stored in the cloud anywhere, anytime possible, requiring only a device with an internet connection (Izumi \& Lopes);

- Reliability: Data access and processing is not dependent on just one server. In many cases, the data is replicated in multiple locations, which increases redundancy and fault independence, thus compromising service (Dias, 2018);

- Security: Cloud computing aims to ensure user data security by storing all documents in the cloud, protecting them through authentication and access data (Dias, 2018);

- Flexibility: Thanks to the resilience power of the cloud, if a company's needs vary, the total capacity of the cloud simply varies. This level of flexibility and adaptability allows companies to gain a competitive advantage over their competitors (Dias, 2018);

- Abstraction: Because all data processing is performed in the cloud, there are no hardware/software compatibility and security issues (Izumi \& Lopes);

- Document collaboration and version control: By allowing you to access, edit, and share documents at any time, the cloud encourages teamwork (Dias, 2018). In addition, working through the cloud enables real-time updates enabling a new relationship with collaborations;

- Storage Capacity: You do not have to worry about storing information as it is not stored on your device (Izumi \& Lopes);

- Automatic updates: A great advantage of cloud computing is that it rests the user on updates, as vendors provide regular system updates, notably for security issues (Dias, 2018). 
Despite the many advantages cloud computing has some disadvantages that should also be taken into account, namely:

- Dependency: Access to all data and information stored in the cloud depend, mandatorily, on an internet connection (Izumi \& Lopes);

- Data/Information Loss: Although the cloud is reliable, there is always the possibility of failures and errors (Izumi \& Lopes);

- Limited options: It is currently not possible to develop very complex software that is capable of processing information outside the local computer that accesses the cloud (Izumi \& Lopes);

- Vulnerability: All data stored in the cloud could be vulnerable to computer attacks even if all precautions are taken (Izumi \& Lopes).

\subsection{Implementation Models}

When implementing a cloud computing infrastructure, it is important to consider the type of information and data that is stored, as well as the business processes and level of vision desired by the company that will use it (Ruschel et al., 2010). The following are the different implementation types:

\subsubsection{Private}

In this deployment model, the cloud is built exclusively for a company that maintains the infrastructure in its internal domain and can be managed by the organization itself or by an external service provider (Zhang, Cheng, \& Boutaba, 2010)(Giraldo, 2018). Private clouds are best suited for companies that deal mostly with sensitive data and have to follow certain specific regulations on data and information security and privacy, such as financial and / or government institutions (Teraware, 2015).

\subsubsection{Public}

Technically, architectural differences between a private and a public cloud may be few, but the control over data and security considerations are fundamentally different in the services offered by the provider to the general public or when communication occurs on an untrusted network (Zhang et al., 2010).

A public cloud is best suited for companies that want to gain technological power with low investments and in short periods of time. For security reasons, it is also more advisable to use it in cases where data is not very sensitive, to host software development platforms or services. (Teraware, 2015).

In short, the main difference between a private and public cloud is that the cloud is integrated into the enterprise and may or may not be physically within the enterprise, but must necessarily be within the firewall and be managed internally by the corporate IT team.

\subsubsection{Hybrid}

In this implementation it is possible to extend the resources of a private cloud from a resource pool in a public cloud, thus sharing data and applications between the two cloud types (Giraldo, 2018). This process has the advantage of maintaining the levels of service provided even when resource utilization needs vary (Ruschel et al., 2010). It also allows give more attention to security processes that require more care, the private party ensures security control through a company-installed restricted network and the remaining additional services are allocated in a public cloud, allowing to balance costs and leverage the resources according to the requests (Zhang et al., 2010). This type of cloud is recommended for companies and customers looking to expand their capabilities beyond their in-house technology capabilities (Teraware, 2015) (Goularte, 2017).

\section{CONCLUSION}

This two concepts, Virtualization and Cloud Computing, are closely linked, in fact, they complement each other. While in the first we are talking about sharing resources, in the second we want to find solutions, in other words, cloud computing comes as a way to monetize this sharing of resources by providing them, to organizations, as services. 
Virtualization is responsible for creating simulated environments and lets you bring together a set of features for a defined purpose. For some companies this is the most suitable solution allowing, for example, cost-reduction. In turn, cloud computing provides storage, networking and other resources with fast and secure access, allowing for use by different departments. Basically, a virtualized environment brings benefits at many levels, leads to better cloud deployment results, and has a big impact on the organization's economy.

\section{REFERENCES}

Alecrim, E. (2012). O que é a virtualização e para que serve? Retrieved from https://www.infowester.com/virtualizacao.php

Carissimi, A. (2008). Virtualização - da Teoria a soluções. Paper presented at the Minicursos do Simpósio Brasileiro de Redes de Computadores - SBRC.

Coelho, F. d. A., Calzavara, G. S., \& di Lucia, R. (2008). Virtualização - VMWare e Xen. Retrieved from https://www.gta.ufrj.br/grad/09_1/versao-final/virtualizacao/origem\%20da\%20necessidade.html

Dias, I. (2018). Cloud computing e a segurança de dados. Retrieved from https://www.jasminsoftware.pt/blog/cloudcomputing-seguranca-dados/

Dunamys. (2017). Virtualização - Definição, Tipos e Benefícios. $\quad$ Retrieved from https://www.dunamys.inf.br/virtualizacao-definicao-e-tipos/

Giraldo, V. (2018). Cloud Computing: o que é, para que serve e como usar no seu negócio? Retrieved from https://marketingdeconteudo.com/cloud-computing/

Goularte, S. (2017). Você sabe o que é Nuvem Híbrida? Retrieved from http://www.scurra.com.br/blog/infraestrutura-eservicos-para-cloud-sobre-nuvem-hibrida/

Guerreiro, C. (2017). Tipos de Virtualização. Retrieved from https://www.portalgsti.com.br/2017/10/tipos-devirtualizacao.html

Izumi, A., \& Lopes, D. Vantagens e desvantagens - Cloud Computing. Retrieved from https://sites.google.com/site/ec1096428411/vantagens-desvantagens

Mattos, D. M. F. (2008). Virtualização - VMWare e Xen. 14.

Menascé, D. A. (2005). Virtualization: Concepts, applications, and performance modeling. Paper presented at the Int. CMG Conference.

O que é Nuvem Pública - Definição. Retrieved from https://azure.microsoft.com/pt-br/overview/what-is-a-public-cloud/

Obasuyi, G., \& Sari, A. (2015). Security Challenges of Virtualization Hypervisors in Virtualized Hardware Environment. International Journal of Communications, Network and System Sciences, 8(8), 260-273. doi:10.4236/ijcns.2015.87026

Ruschel, H., Zanotto, M. S., \& da Mota, W. C. (2010). Computação em Nuvem. 15.

Saleem, M. (2017). Cloud Computing Virtualization. International Journal of Computer Applications Technology and Research, 6(7), 290-292.

Sareen, P. (2013). Cloud Computing - Types, Architecture, Applications, Concerns, Virtualization and Role of IT Governance in Cloud. International Journal of Advanced Research in Computer Science and Software Engineering, 3(3), 533-538.

Shields, G. (2011). How are presentation virtualization and desktop virtualization different? Retrieved from https://www.itprotoday.com/server-virtualization/q-how-are-presentation-virtualization-and-desktop-virtualizationdifferent

Souza, B., Borge, G., Borges, R. G., \& Assis, L. (2016). Formas de Virtualização e suas vantagens e desvantagens. Retrieved from http://administracaoservidoresinfo.blogspot.com/2016/12/formas-de-virtualizacao-e-suas.html

Teraware. (2015). Conheça os diferentes tipos de Cloud Computing. Retrieved from http://portal.teraware.com.br/conheca-os-diferentes-tipos-de-cloud-computing/

Zhang, Q., Cheng, L., \& Boutaba, R. (2010). Cloud computing: state-of-the-art and research challenges. Journal of Internet Services and Applications, 1(1), 7-18. doi:10.1007/s13174-010-0007-6 